\title{
The uncertainty effects of design flow on water quality management
}

\author{
Chi-Feng Chen • Hwong-Wen Ma
}

Received: 2 April 2007 / Accepted: 28 August 2007 /Published online: 22 September 2007

(C) Springer Science + Business Media B.V. 2007

\begin{abstract}
In water quality management, pollution control strategies have been sought to accord with the assimilative capacity of water bodies so as to preserve water quality. The waste load allocation (WLA) is a useful approach to determine the allowable loading of pollution sources in water quality management. For any WLA, a particular water body condition is needed as a basic scenario under which the relevant parameters are fixed. The particular flow rate is known as design flow and usually set at low flow in order to be protective. The design flow is traditionally a particular deterministic value, such as $Q_{75}$, implying that it is expected that the probability of water quality violation is $25 \%$ in the long run. However, this long-term expectation might not be realized in individual years due to variability of natural flow. The flow variability will make a WLA plan overoptimistic or over-conservative in different years, suggesting that the deterministic design flow without uncertainty consideration might lead to an ineffective or inefficient decision-making. To address the problem, we explicate the relationship between flow variability, design flow and water quality with different flow distributions to facilitate the under-
\end{abstract}

C.-F. Chen · H.-W. Ma $(\bowtie)$

Graduate Institute of Environmental Engineering,

National Taiwan University,

71 Chou-Shan Road,

Taipei 106, Taiwan

e-mail: hwma@ntu.edu.tw standing of the process of a WLA. In order to manifest the uncertainty effects of design flow, the results from the annual flow duration curve (AFDC) is compared with the conventional flow duration curve (FDC). The AFDC approach is capable of obtaining the uncertainty level of the design flow by generating the confidence interval rather than a fixed value. The effect of different record lengths on design flow determination is estimated as well. Finally, a refined WLA process is proposed with a re-examination of water quality violation to improve the allocation decision under uncertainty. TaHan River Basin in northern Taiwan is used as a case study.

Keywords Design flow . Flow variability . Uncertainty analysis · Waste load allocation (WLA) . Annual flow duration curve (AFDC)

\section{Introduction}

In any water quality management, the relationship between pollution control and water quality is always being sought by analytic methods in order to ensure a successful implementation. Reducing pollutions to restore impaired water quality or to maintain desirable water environment is the major focus in a water quality management. The waste load allocation (WLA), a critical step in the Total Maximum Daily Loads (TMDLs) program, is a systematic process to 
planning pollution sources control. Permissible discharges or removal rates will be assigned to pollution sources in a watershed through the WLA process. Before proceeding to a WLA process, a particular waterbody condition is set as the basic scenario, including in particular the assignment of stream flow, called design flow, to take account of assimilative capacity of receiving waterbodies. Such basic information is usually treated as a 'certain premise' without further investigations, and the uncertainty effects of design flow have rarely been addressed. However, this value has significant influence on the decision of WLA. When the pollutant concentration in a stream is limited by water quality criteria, the allowable loading is determined by the flow of waterbody, since a larger design flow allows more pollution discharges into waterbody under the same water quality criteria and a smaller one restricts pollution discharges. Once the allocation is decided under the design flow condition, the realized water quality will not be a constant concentration, but will change with varying stream flow. Therefore, because of natural variability and measurement error, the use of the design flow without consideration of uncertainty would mislead a WLA and a TMDL program.

A general consensus about the use of design flow is to use low flow rate in order to protect water environment quality with a marginal safety (Smakhtin 2001). For example, $Q_{7,10}$ in the U.S. and $Q_{75}$ in Taiwan are often used. The low flow is often estimated by the magnitude and frequency of streamflows and presented by probability, such as exceedance percentage or return period. It is used as a deterministic value. However, uncertainty occurs in flow records, such as length of records, imprecision measurement, and missing data (Smakhtin 2000; Yu et al. 2002); there is a need to review adequacy of the use of design flow. The uncertainty of design flow can be summarized as two parts: flow variability and calculation error. Flow variability has been discussed more than calculation error of design flow and has been well documented by hydrologists (Lence and Takyi 1992; Salas and Obeysekera 1992; Hakanson 1996; Kao and Bau 1996; Chaleeraktrakoon 1999; McCuen and Beighley 2003). Although the uncertainty related to other model parameters has received much concern and even sampling plans and management approaches have been designed to deal with the uncertainty, the uncertainty of design flow has rarely been discussed in water quality control policy. The waste allocation is processed under a fixed design flow condition; the resulting realistic water quality might not achieve the expected level due to randomness of natural flow. To enhance understanding of the effects of design flow on WLA, the relationships of flow variability, design flow, and water quality violation is clarified in this study.

Rather than obtaining a constant value, the feasible range of the design flow derived from uncertainty analysis should be considered. However, due to the limitation of the traditional approach, such as flow duration curve (FDC), the uncertainty of design flow is not revealed. FDC is a curve displaying the relationship between the magnitude and frequency of daily or weekly or monthly streamflow and provides the percentage of time that the streamflow is equal to or exceeds a given streamflow over a historical period (Vogel and Fennessey 1994, 1995; Smakhtin 2001; $\mathrm{Yu}$ et al. 2002; Castellarin et al. 2004a, b). For example, $Q_{75}$ refers to more than $75 \%$ stream flow exceeding this value. FDC is widely used on water resource engineering, water quality management, hydropower generation, flood control and irrigation systems (Vogel and Fennessey 1995). However, a quantile from FDC, such as $Q_{75}$, is a deterministic value without discussion of the variability or precision. As Vogel and Fennessey (1994) described, “... the FDC does not, by itself, expose the uncertainty associated with a particular quantile estimate." In addition, the lower tail of FDC curve is highly sensitive to the particular records. For this reason, Vogel and Fennessey (1994) developed a new annualbased FDC known as AFDC, which is capable of deriving the confidence interval of flow of each quantile in a nonparametric framework. Although the stochasticity of FDC has been characterized in the literature (LeBoutillier and Waylen 1993; Cigizoglu and Bayazit 2000; Castellarin et al. 2004b), its effects on WLA have not been explored. This study, therefore, evaluates the uncertainty of design flow by AFDC and assesses its effects on final WLA decisions with a real case study.

Following the proposed relationship of design flow and WLA and the result of the case study, a modified WLA process that incorporates an additional examination of water quality after allocations to mitigate uncertainty effects is consequently established. The revised WLA framework is aimed to improve 
effectiveness of the performance. In the rest of this paper, "Materials and methods" describes the methodology, including the WLA process, FDC, AFDC, and the case study. The analysis results of uncertainty and variability of the design flow and the associated influence on waste loads allocation is addressed and discussed in "Results and discussions". Finally, conclusions and suggestions are drawn in "Conclusion".

\section{Materials and methods}

This study framework consists of three main parts, including a complete WLA procedure, calculation of uncertainty of design flow, and a proposed modified WLA process. In the WLA process, an optimal pollution allocation plan is formulated. The uncertainty of the design flow is quantified by FDC and AFDC, and is incorporated into the WLA as an uncertain input parameter. The uncertainty effects of the design flow on WLA can then be visualized. Finally, according to the obtained allocation scheme, the performance of WLA is re-examined in various individual years to assess its effectiveness and to adjust the WLA decision. TaHan River Basin in northern Taiwan is investigated as a case study. The methods, WLA, FDC, and AFDC, and the description of the case study are addressed as follows.

Waste load allocation process (WLA)

Waste load allocation (WLA) is an optimization strategy that identifies how much loading each pollution source is allowed to discharge to receiving waterbodies without exceeding water quality standards. Based on the quantitative relationship between pollution sources and receiving waterbodies, a WLA determines the required treatment levels and the allowable loadings for all point and nonpoint pollution sources to reach desired water quality (Burn and Lence 1992; Warwick and Roberts 1992; Mahajan et al. 1999). Playing an important role in TMDL, WLA can either facilitate or frustrate implementation of TMDL. An inadequate WLA makes a TMDL program improper since an overestimated allocation implies unnecessary resources use and loss of economic efficiency. An underestimated allocation, on the contrary, might discharge pollution loadings beyond the assimilative capacity of waterbodies and fail to protect water quality. To ensure economic efficiency and water quality improvement demands accurate simulation and rational optimization, both of which constitute the main structure of a WLA. Because the WLA is composed of a simulation model and an optimization programming, it is recognized as an S-O model (Carson and Maria 1997; Neelakantan and Pundarikanthan 2000; Mujumdar and Vemula 2004). Simulation models predict water quality and provide necessary parameters such as water quality impact coefficients for the subsequent optimization programming. The allowable loadings of each source are computed under specific policy objectives. There are many allocation methods, and the primary objectives are maximum economic efficiency, equity, and water quality improvement. The typical WLA process is sketched as Fig. 1.

In this study, a verified River and Stream Water Quality Model, QUAL2K (Chapra and Pelletier 2003), is employed to simulate water quality. QUAL2K model is the updated version of QUAL2E, which is the most widely used water quality model. The QUAL2K model is built with Excel VBA and has several advantages over QUAL2E, such as new constituent evaluations and the expansion of the modeling structure. More detailed comparison between QUAL2E and QUAL2K can be found in Park and Lee (2002).

To clarify the difference of WLA decision in response to uncertainty of design flow, the objective function is set as minimization of equal treatment removal rate (ETR) in the optimization programming. In the optimization programming, the primary con-

\section{$\underline{\text { S-O model }}$}

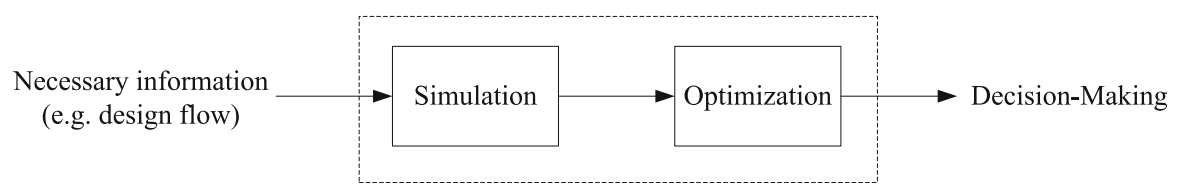

Fig. 1 A typical WLA process, including a simulation model and optimization programming (S-O model) 
straint is the water quality limitation, in which the pollution concentrations at checkpoints are required to comply with the water quality criteria. Using biochemical oxygen demand (BOD) as the target pollutant, the optimization formulations are as follows.

Minimum $r$

subject to

$$
\begin{aligned}
C_{j} & -\sum_{i=1}^{N} A_{i j} \times W_{i} \times r \\
& \leq S_{j} \text { (waterqualitylimitation) } \\
R^{\mathrm{L}} & \leq r \leq R^{\mathrm{U}} \text { (constraintsonvalueofr) }
\end{aligned}
$$

\section{All variables $\geq 0$ (nonnegativeconstraints)}

where $r$ is the removal rate that applies equally to every source. $C_{j}$ is the $\mathrm{BOD}$ concentration at checkpoint $j(\mathrm{mg} / \mathrm{l}), A_{i j}$ is the impact coefficient of source $i$ to checkpoint $j$ (the details and unit of this value are addressed in the next section.), $W_{i}$ is the BOD load of source $i(\mathrm{~kg} /$ day $), S_{j}$ is the water quality standard at checkpoint $j(\mathrm{mg} / \mathrm{l})$, and $N$ is the number of sources. ( $N$ is equal to four in this study.) $R^{\mathrm{U}}$ and $\mathrm{R}^{\mathrm{L}}$ are the upper and lower bounds of the removal rate, respectively.

It should be noted that the key linkage of the simulation model and the optimization programming is the impact coefficient $\left(A_{i j}\right)$. The impact coefficient represents the individual water quality impact caused by each pollution source, referring to the change of pollutant concentration at checkpoint $j$ in the waterbody caused by a unit loading of source $i$. It is obtained from the Eq. 5 based on the resulting water quality of the simulation model and then becomes the input for the subsequent optimization programming.

$A_{i j}=\left(C_{j p}-C_{j n}\right) / W_{i}$

where $C_{j p}$ is the BOD concentration at checkpoint $j$ under all discharges (in $\mathrm{mg} / \mathrm{l}$ ), $C_{j n}$ is the BOD concentration at checkpoint $\mathrm{j}$ without discharge of source $i$ (in $\mathrm{mg} / \mathrm{l}$ ), and $W_{i}$ is the BOD loading of source $i$ (in $\mathrm{kg} /$ day).
Flow duration curve (FDC) and annual-FDC (AFDC)

Flow duration curve (FDC) depicts the occurrence probability of streamflow and derives the exceedance percentage of flow rates according to historical records. To calculate FDC, one might use different time scales of interest and produce several types of FDC. Daily, weekly, or monthly flow rates can be used, but the period of record daily FDC that covers the complete record of flows is the most commonly used (Vogel and Fennessey 1994). The average monthly FDC is extracted from the same or similar months flow and can be extended to average seasonal FDC if one is concerned with the seasonal variability (Smakhtin 2001). The graphic FDC provides an easy way to capture comprehensive information about the variability of streamflow in terms of the quantity and frequency of streamflow. The low flow, such as the design flow of concern, is given by the tail of FDC, in which the large exceedance percentage implies that most streamflows are equal or larger than the given flow.

An FDC can be constructed in two steps: (a) ranking all the observed stream flows from the largest to the smallest, $q_{i}, i=1,2, \ldots, n$, where $\mathrm{n}$ is the data length; (b) finding the corresponding probability of exceeding individual flow $i, p_{i}$, as Eq. 6 (Vogel and Fennessey 1994). Weibull method is used in this study.

$p_{i}=P\left(Q>q_{i}\right)=1-P\left(Q \leq q_{i}\right)$

An annual FDC (AFDC) is generated by the same steps as FDC except the use of each individual year data. The AFDC was developed for the purpose of complementing information of uncertainty associated with each quantile of FDC. In AFDC computation, the flow data of all period years are decomposed into individual years and the FDCs for individual years are calculated. Assuming $Q_{p}(i)$ is the stream flow of the $p$ th quantile in the year $i$, then $n Q_{p}$ are generated given n years of data. Every new $Q_{p}$ set is assumed normally distributed and the $95 \%$ confidence interval of a mean $Q_{p}$ can be calculated. After calculating the confidence interval for the set of flow at each quantile, the AFDC curve is formed and the confidence interval of each exceedance probability $p$ is revealed. The detail of AFDC computation was described in Vogel and Fennessey (1994). In addition to unveiling the confidence interval for the benefit of uncertainty considerations, AFDC can also resolve a 
traditional dilemma of FDC. Since the FDC is drawn from a selected period of records, the derived low flow has been challenged about its rationality. The median AFDC, however, represents the median streamflow in a typical year and is not affected by observation record length. AFDC is less sensitive to data length and thus moderates the influence caused by using particular periods of years. The approach provides useful information that can not be obtained by the traditional FDC, especially the uncertainty of the design flow estimate.

Description of the case study

To clarify the concept of this study, a river basin suffering from point pollution sources is a better example than a watershed contaminated primarily by nonpoint sources because the allocation between point and nonpoint pollution in WLA is not perfectly integrated. Therefore, we use TaHan River basin in northern Taiwan as a case study (Fig. 2), where the domestic and industry wastewater contribute more than $90 \%$ pollutions into the waterbody. The TaHan River is $135 \mathrm{~km}$ in length and the river basin covers $1,163 \mathrm{~km}^{2}$. The biochemical oxygen demand
(BOD) is the pollutant of concern to represent waste discharges of domestic wastewater in Taiwan. According to the water quality standard, the BOD concentration in the TaHan River should be maintained under $4 \mathrm{mg} / \mathrm{l}$, but the average value is over $5 \mathrm{mg} / \mathrm{l}$. Therefore, the TaHan River is classified as light pollution level. Due to the Q2K model is based on ultimate CBOD (carbonaceous BOD), a converting process based on an exponential relationship with CBOD decomposition rate is applied according to the Q2K user's manual (Chapra and Pelletier 2003).

Although some water quality improvement strategies have been applied to this area, a complete waste load allocation has not been implemented. In a previous study, the BOD discharge was suggested to be reduced by $80 \%$ to meet the water quality standard (Chang 2005). Haung (2005) also studied the optimal sanitary sewer collection rate on non-tidal TaHan River with QUAL2K model and concluded that the collection rate should be 30 to $85 \%$. The information collected in Haung (2005) study, including pollution sources and verified model parameters is employed in this work. The distribution of pollution sources is depicted in Fig. 3 and the pollution data is summarized in Table 1.
Fig. 2 The location of TaHan River Basin in Taiwan

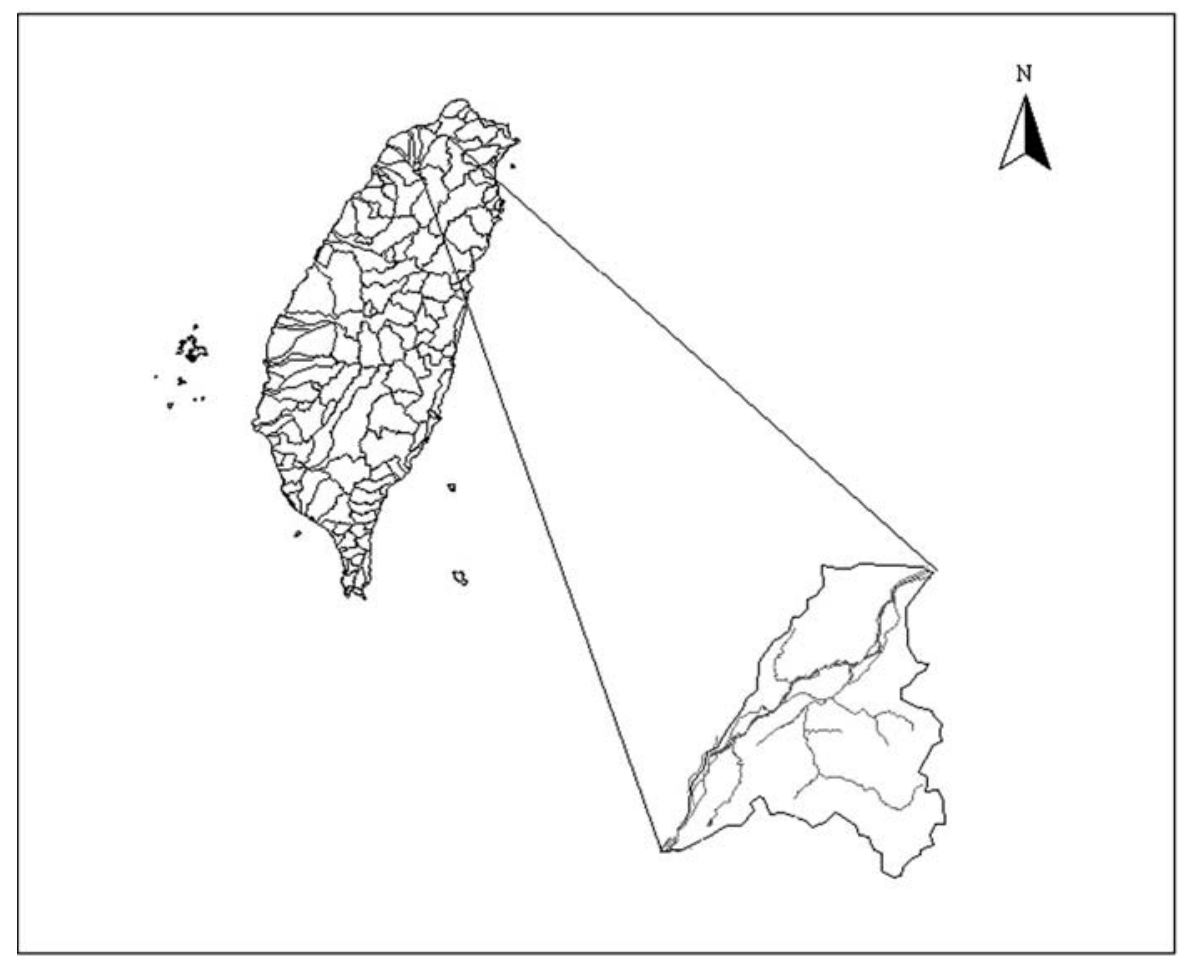


Fig. 3. The distribution of point pollution sources $(i=\mathrm{A}, \mathrm{B}, \mathrm{C}, \mathrm{D}$, and $\mathrm{E})$ and checkpoints $(j=\mathrm{a}, \mathrm{b}, \mathrm{c}, \mathrm{d}$, and e) in TaHan River Basin

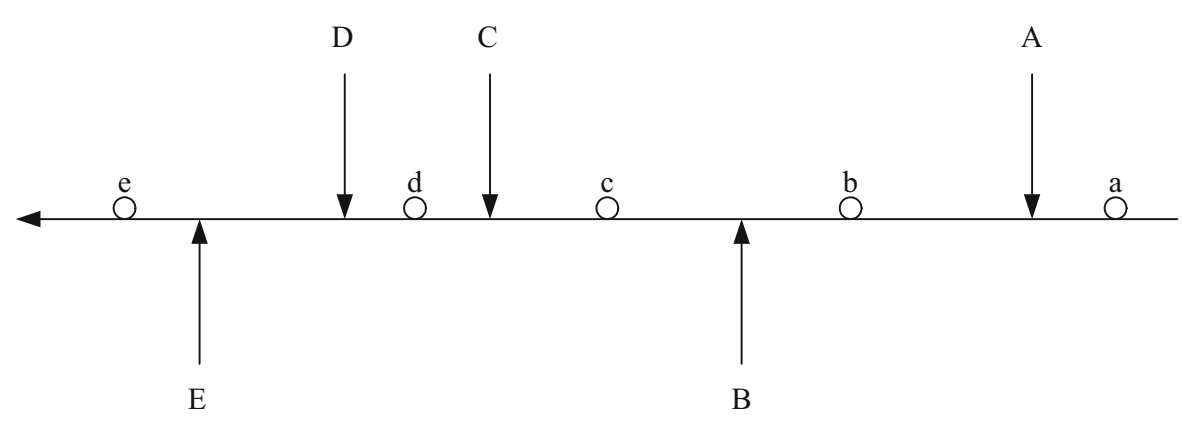

\section{Results and discussions}

The uncertainty analysis of design flow

The streamflow records of TaHan River from 1980 to 2002 are used as our flow data. The result of period-of-years FDC for the 23 record years in daily flow is drawn as Fig. 4 and the flow corresponding to exceedance probability $75 \%\left(Q_{75}\right)$ extracted from the curve is $12.25 \mathrm{cms}$. Figure 4 also shows the output of AFDC. The $95 \%$ confidence interval ranges from 14.78 to $10.84 \mathrm{cms}$, and the mean $Q_{75}$ is $12.81 \mathrm{cms}$, which is very close to the result of period-of-years FDC. In the AFDC curve, the standard deviations of high stream flows are much larger than those of low stream flows, which is due to the climate variability. The heavy storms often appear in wet seasons (i.e. from May to October), causing the larger variance in higher stream flow, but the variability is not so distinct for lower flow in dry seasons. We did not further evaluate the season variability in this work, but the seasonal discharge management has been suggested by $\mathrm{Gu}$ and Dong (1998).

The record length used has been regarded as a factor causing uncertainty in the design flow. Therefore, we calculate design flow with $5,10,15$, and 23 years of data. The results are summarized in

Table 1 The characteristics of each pollution source

\begin{tabular}{llrl}
\hline $\begin{array}{l}\text { Pollution } \\
\text { source }\end{array}$ & $\begin{array}{l}\text { Discharge } \\
(\mathrm{cms})\end{array}$ & $\begin{array}{r}\mathrm{BOD}_{5} \\
(\mathrm{mg} / \mathrm{l})\end{array}$ & Waste loads (Wi, kg/day) \\
\hline A & 0.296 & 64.75 & 1,656 \\
B & 0.278 & 195.64 & 4,699 \\
C & 0.509 & 155.95 & 6,858 \\
D & 0.317 & 171.68 & 4,702 \\
E & 0.250 & 182.24 & 3,936 \\
\hline
\end{tabular}

Table 2. The standardization is utilized for the purpose of comparing different record lengths regarding a particular design flow. For example, the standardized values of $Q_{50}$ in 5-year record length and in 23 year record length are 1.47 and -0.32 , respectively. This means the use of five record years produces higher design flow than 23 record years used by about the quantity of 0.8 standard deviation. Using standardized value is convenient for revealing the design flow variability across different record lengths. The results show that the use of recent 5 years data (1998-2002 year) as record length generates relatively larger design flow and the corresponding standardized value is 1.3 to 1.5 . The similar design flow is obtained from the record length of 10 and 15 years and their standardized values are between -0.40 and -0.95 . The design flows estimated from all period of record year (23 years) are close to the average value. Therefore, the design flow is more sensitive and reflects more truly situations in the short-term year period case (five years in this study). When the record lengths of 10 or 23 years are used in assessing a long-term period, the calculated design flows are similar. Table 2 also implies that different record lengths cause the difference in $Q_{50}, Q_{75}$, and $Q_{90}$ by 13,9 , and $17 \%$, respectively. The sensitivity of record length for lower flow is more significant. In summary, the use of record length might lead to a variance of design flow by about $10 \%$. Therefore, the decision maker should pay heed to the use of record length in terms of short-term or long-term period to plan an adequate WLA for future situations. When considering a long-term management in the case study, the use of data length of 10 years is capable of showing the flow condition. However, to plan a short-term WLA for the case, the use of 5 years data length will be suggested in order to reflect the flow trend. The suggested use of flow data length might be 
Fig. 4 The flow duration curve $(F D C)$ and the annual FDC $(A F D C)$ of the case study
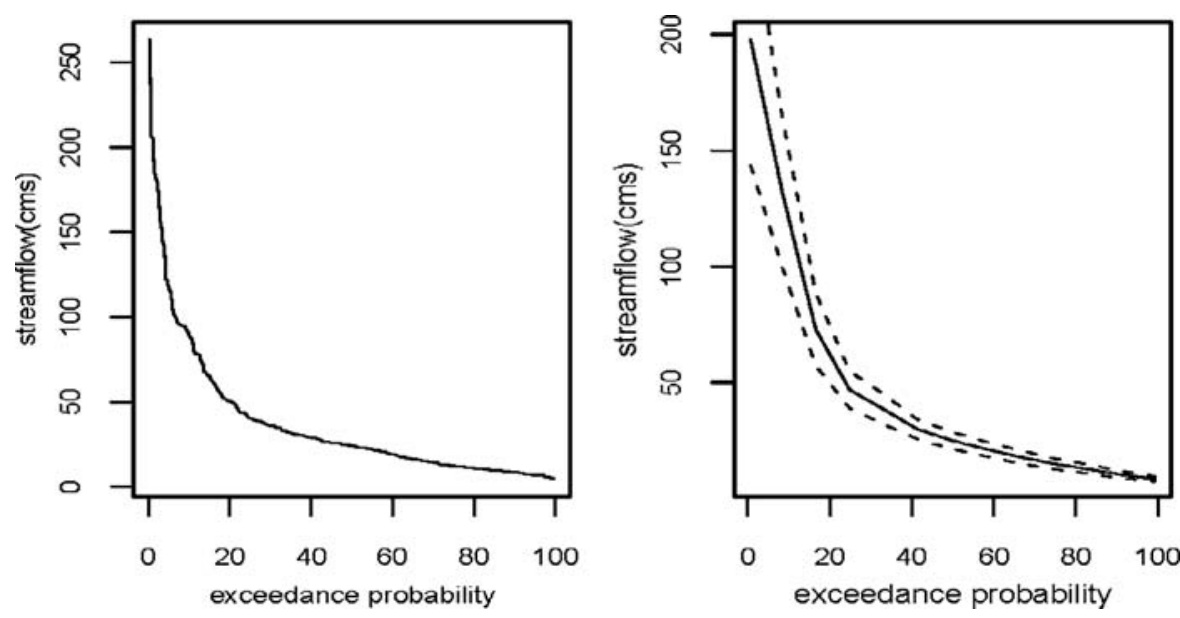

case-dependent, and the temporal flow variability should be considered in any WLA plans.

The effects of the design flow's uncertainty on WLA

The $Q_{75}$ obtained from FDC evaluation and the confidence interval calculated from AFDC are used to calculate uncertainty effects of design flow on pollutant removal rates in the WLA decision. Through the WLA process, the $\mathrm{S}-\mathrm{O}$ model, the removal rate required for each pollution sources is calculated. The parameters in QUAL2K are treated as certain, using the available local data and model defaults (Haung 2005) except the headwater flow is subject to the uncertainty analysis of design flow.

According to optimization programming of Eqs. 1, 2, 3, to 4 , the data of BOD concentration at checkpoints $\left(C_{j}\right)$, the impact factors $\left(A_{i j}\right)$, waste loads of sources $\left(W_{i}\right)$, and water quality standard $\left(S_{j}\right)$ are needed. The $W_{i}$ is included in Table 1 and $S_{j}$ is assigned as $4 \mathrm{mg} / \mathrm{l}$ based on the water quality standard. The $C_{j}$ and $A_{i j}$ are derived from Q2K model and change with different $Q_{75}$ conditions. LINDO (Linear, INteractive, and Discrete Optimizer) is used to solve the linear programming. The optimal removal rates for different design flow conditions are estimated and illustrated as Fig. 5. Unsurprisingly, the removal rate decreases with increasing design flow, and its value ranges from $81 \%$ to $94 \%$. It indicates that the uncertainty of the design flow leads to a $13 \%$ difference and affects the WLA decision directly. The magnitude of the difference is similar to the margin of safety (MOS) in TMDL programs, which is conventionally assigned as $10 \%$. The above analysis points out the importance of designation of design flow, and suggests that the assumption of flow condition prior to modeling process should not be decided without uncertainty analysis.

Table 2 Different design flows in different lengths of record years (unit: cms)

\begin{tabular}{|c|c|c|c|c|}
\hline $\begin{array}{l}\text { record year period } \\
\text { record length }\end{array}$ & $\begin{array}{l}1998-2002 \\
5\end{array}$ & $\begin{array}{l}1993-2002 \\
10\end{array}$ & $\begin{array}{l}1988-2002 \\
15\end{array}$ & $\begin{array}{l}1980-2002 \\
23\end{array}$ \\
\hline$Q_{50}$ & $23.06(1.47)^{\mathrm{a}}$ & $20.45(-0.40)$ & $19.95(-0.75)$ & $20.55(-0.32)$ \\
\hline$Q_{60}$ & $18.30(1.44)$ & $15.98(-0.57)$ & $15.75(-0.77)$ & $16.54(-0.09)$ \\
\hline$Q_{70}$ & $14.39(1.40)$ & $12.85(-0.83)$ & $13.01(-0.60)$ & $13.45(0.04)$ \\
\hline$Q_{75}$ & $12.85(1.36)$ & $11.75(-0.90)$ & $11.91(-0.58)$ & $12.25(0.12)$ \\
\hline$Q_{80}$ & $11.98(1.43)$ & $10.63(-0.85)$ & $10.85(-0.48)$ & $11.08(-0.09)$ \\
\hline$Q_{90}$ & $10.02(1.39)$ & $8.34(-0.92)$ & $8.674(-0.47)$ & $9.02(0.01)$ \\
\hline
\end{tabular}

\footnotetext{
${ }^{\mathrm{a}}$ The values in parentheses are the standardized values of the calculated design flows.
} 
Fig. 5 The relationship between uncertainty of $Q_{75}$ and pollutant removal rate without consideration of other uncertainties

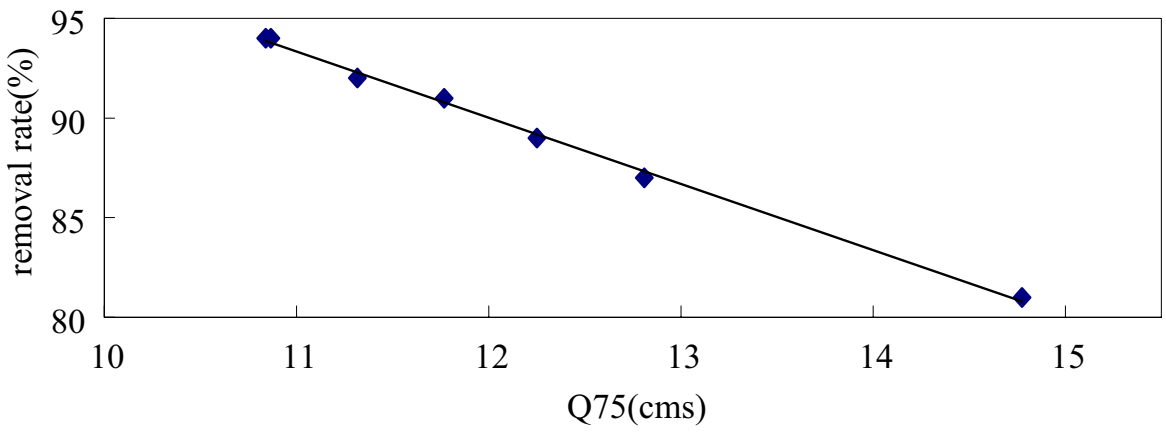

The effects of flow variability on WLA

Ideally, the violation of water quality standards is consistent with the exceeding probability of design flow. For example, the $Q_{75}$ represents that $25 \%$ stream flow would be less than this value and there would be a $25 \%$ probability that the water quality exceeds the standards if other uncertainties are ignored. However, for individual years, the violation ratio in reality may not achieve this expectation because of the natural flow variability. For example, given the $Q_{75} 12.25 \mathrm{cms}$ and the removal rate $89 \%$, the daily flow in the past five years (1998-2002) are used to test the effects of flow variability on water quality. Among the five checkpoints (i.e., a, b, c, d, and e.), the water quality at the downstream is the worst, so the results of checkpoint e are used for subsequent discussions. In Fig. 6, no BOD violation occurs in the five years under this scenario. However, when the upper boundary of the $95 \%$ confidence interval of $Q_{75}$ from AFDC is set as the design flow, which is $14.78 \mathrm{~cm}$, the violation percentage increases dramatically. Because the natural flow in 2002 is much lower than that in other years, this year's violation percentage of water quality goes up to $60 \%$.

Although there is no violation in any days under the use of the $Q_{75}$ of traditional period-of-year FDC, it does not mean that an appropriate WLA has been used. Rather, it might imply unnecessary treatment cost being wasted. According to the assessment rule for listing an impaired water body in the USA, it allows a margin of $10 \%$ violation (Smith et al. 2001; Shabman and Smith 2003). That might indicate that the simulation of water quality in five years allows roughly 180 days of violation, which, although with over-interpretation, provides a simple way to check the appropriateness of the use of design flow in water quality management.

Besides the $Q_{75}$, other design flows, such as $Q_{80}$ and $Q_{90}$, can be assessed in the same way. Figure 7 illustrates the results of exceeding probability of water quality in the past five years. If the $10 \%$ rule is used, the optimal design flow locates between $Q_{70}$ and $Q_{75}$, with corresponding removal rate of 81 and $89 \%$, respectively. Therefore, $85 \%$ might be a reasonable removal rate in the case study.
Fig. 6 The relationship between $Q_{75}$ (the value from FDC and from the upper 95\% confidence interval of AFDC) and violation of water quality criteria, $\mathrm{V} \%$, in different individual years

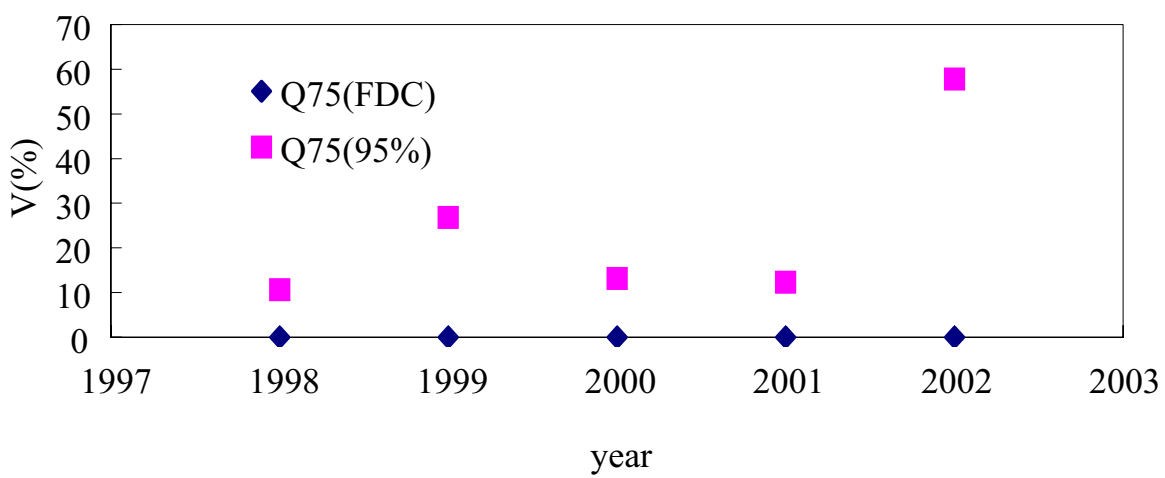


Fig. 7 The relationship between exceeding probability of design flow and violation of standards, $V \%$, at a downstream checkpoint in 5 years

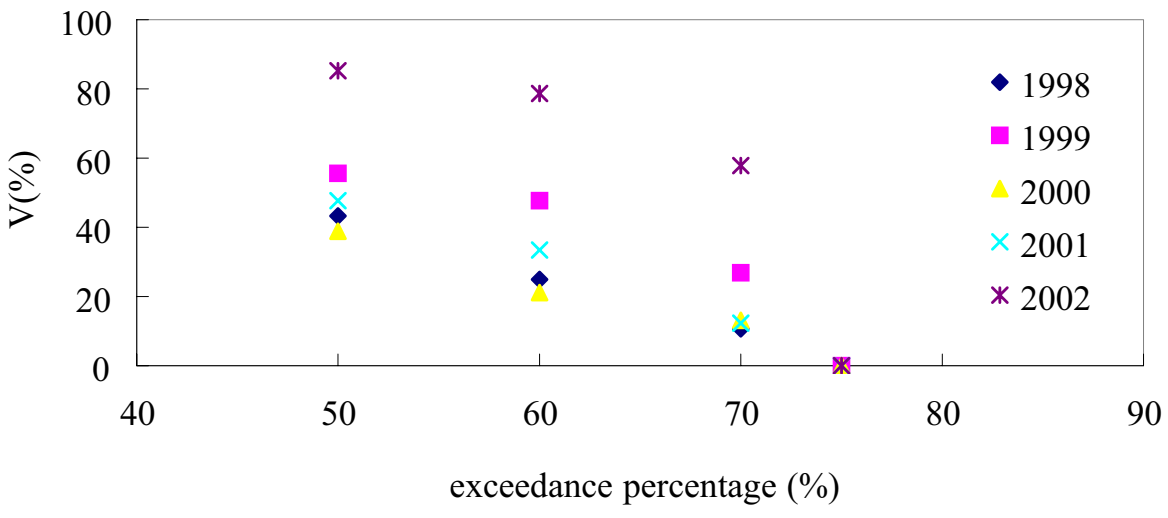

In the light of the effect of design flow on WLA, we then suggest that the WLA processes as shown in Fig. 1 may be modified to be like Fig. 10, in which the confidence level of the design flow and the examination of water quality violation are included. The uncertainty analysis of design flow supports us with the confidence level of the performance of waste load allocation. Based on the information, the optimal design flow should be determined by considering the tradeoff between treatment cost and water quality
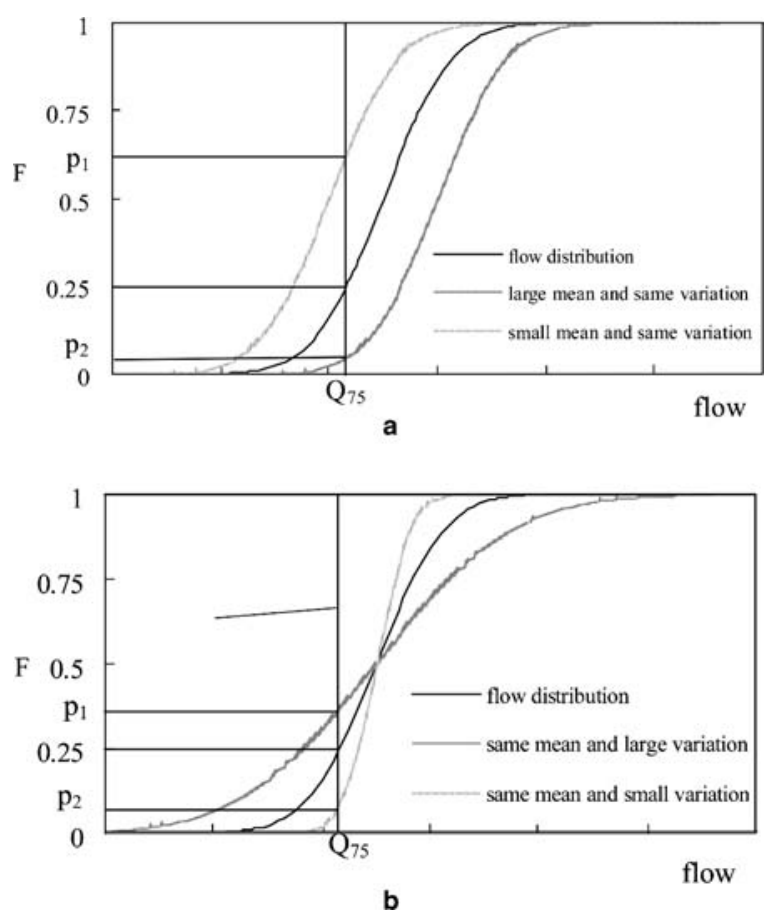

Fig. 9 Comparison of the cumulative probability distributions of different flows: those with the same variation with different average values (a), and those with the same average value and different variations $(\mathbf{b})$
Fig. 8 The relationship between design flow and flow distribution 


\section{$\underline{\text { S-O-S model }}$}

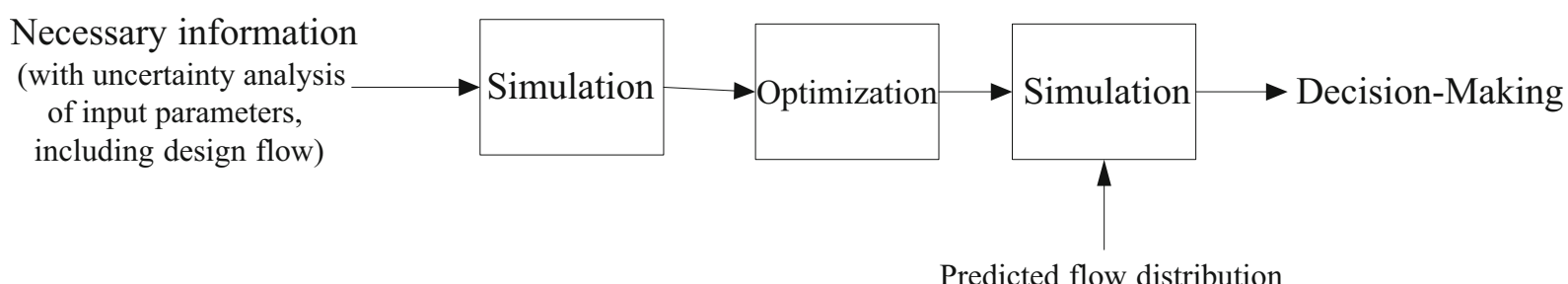

Fig. 10 The modified WLA process, S-O-S model, which incorporates uncertainty analysis of the design flow and re-simulation of water quality

violation. In Fig. 10, the original $\mathrm{S}-\mathrm{O}$ model is advanced to an $\mathrm{S}-\mathrm{O}-\mathrm{S}$ model. The new $\mathrm{S}-\mathrm{O}-\mathrm{S}$ model incorporates an additional simulation process to evaluate the optimal WLA with the predicted flow distribution. This step is designed as a mechanism to adjust or to predict the adequacy of the WLA decision. A complete WLA process should not stop at the final optimization decision; a post-audit simulation with predictive future flow condition under uncertainty considerations will support the risk information of the WLA implementation.

\section{Conclusion}

This study quantifies the influence of the uncertainty of the design flow on waste loads allocation. In TMDLs, a WLA is the step for deciding the optimal allowable loadings for each pollution source; in the step, a particular flow condition, known as the design flow, is required as a basic scenario. Unlike other model parameters, the design flow has not been set as an uncertain input; it is always set as a fixed value for subsequent WLA steps. However, due to presence of uncertainty associated with this design flow, it is not a deterministic value and might lead to an over-conservative or over-optimistic WLA policy. This study therefore assesses the design flow's importance in terms its effect of flow variability and calculation error.

The traditional FDC is not able to derive the uncertainty level of design flow. Thus, an annual FDC (AFDC) is employed to compute the confidence interval of the design flow to support the deterministic results of the conventional FDC method. The case study shows that the calculation error from FDC causes a $13 \%$ difference on waste load allocation, roughly equivalent to the traditionally assigned margin of safety (MOS) in TMDLs, $10 \%$. Besides, the use of record lengths leads to difference in design flows by about $10 \%$. Therefore, the uncertainty of the design flow would contribute up to $20 \%$ variation to the WLA decision. In addition, the expected violation probability, such as $25 \%$ for $Q_{75}$, may not be realized in individual year due to flow variability. Because of the uncertainty and variability, the evaluation of water quality violation after allocation is suggested to be integrated into a WLA process. Hence, an S-O-S model is proposed to advance the typical WLA process, which is an S-O model. A water quality report is surveyed regularly every two years in the U.S.; therefore, the realizations of water quality in past 5 or 2 years would be helpful for adjusting the design flow and determining the allocation under the uncertain flow condition. The examination of water quality violation percentage shows that it might lead to an improper management due to overestimation or underestimation if the uncertainty of the design flow is ignored.

It should be noted that several uncertainties can be found in a WLA process, such as model uncertainty and parameter uncertainty in simulation and linguistic vagueness in optimization, causing the decision of waste allocation uncertain. For example, the designation of adequate water quality criteria is a key issue (Reckhow et al. 2005) involved in WLAs, and NRC (2001) suggested the numerical criteria should be decided based on site specific conditions to seek the most feasible standard. The background streamflow, discharge effluences, and pollution concentrations also change with time and space. Regarding modeling tasks, the uncertainty of model parameters are the most concerned uncertainty causes and has been heavily documented. Clarifications of uncertainty effects of each item are helpful in advancing 
effectiveness of water quality management. This study is focused on the uncertainty effects of design flow without incorporating other uncertainties. Some valuable information about the other uncertainties was addressed in Aalderink et al. (1996), Melching and Yoon (1996), and Osidele et al. (2003), etc.

\section{References}

Aalderink, R. H., Zoeteman, A., \& Jovin, R. (1996). Effect of input uncertainties upon scenario predictions for the River Vecht. Water Science and Technology, 33(2), 107-118.

Burn, D. H., \& Lence, B. J. (1992). Comparison of optimization formulations for waste-load allocations. Journal of Environmental Engineering, 118(4), 597-612.

Carson, Y., \& Maria, A. (1997). Simulation optimization: methods and applications. Proceedings of the 1997 Winter Simulation Conference, pp 118-126.

Castellarin, A., Galeati, G., Brandimarte, L., Montanari, A., \& Brath, A. (2004a). Regional flow-duration curves: reliability for ungauged basins. Advances in Water Resources, 27, 953-965.

Castellarin, A., Vogel, R. M., \& Barth, A. (2004b). A stochastic index flow model of flow duration curves. Water Resources Research, 40(3), W03104.

Chaleeraktrakoon, C. (1999). Stochastic procedure for generating seasonal flows. Journal of Hydraulic Engineering, 4(4), 337-343.

Chang, C. K. (2005). Pollution source survey and prevention program assess for the Ta-Han river Basin. 96 pp. Master Thesis, Graduate Institute of Environmental Engineering, National Taiwan University, Taiwan (in Chinese).

Chapra, S. C., \& Pelletier, G. J. (2003). QUAL2K: A modeling framework for simulating river and stream water quality: documentation and user's manual. $121 \mathrm{pp}$. Civil and Environmental Engineering Dept., Tufts University.

Cigizoglu, H. K., \& Bayazit, M. (2000). A generalized seasonal model for flow duration curve. Hydrological Processes, 14, 1053-1067.

Gu, R., \& Dong, M. (1998). Water quality modeling in the watershed-based approach for waste load allocations. Water Science and Technology, 38(10), 165-172.

Hakanson, L. (1996). A new, simple general technique to predict seasonal variability of river discharge and lake temperature for lake ecosystem models. Ecological Modelling, 88, 157-181.

Haung, T. I. (2005). QUAL2K Applied on the dervation of the optimal sanitary sewer collection rates in the Non-tidal influenced section of Damshui River. 109 pp. Master Thesis, Department of Safety, Health and Environmental Engineering, National United University, Taiwan (in Chinese).

Kao, J. J., \& Bau, S. F. (1996). Risk analysis for flow duration curve based seasonal discharge management programs. Water Research, 30(6), 1369-1376.

LeBoutillier, D. W., \& Waylen, P. R. (1993). A stochastic model of flow duration curves. Water Resources Research, 29(10), 3535-3541.

Lence, B. J., \& Takyi, A. K. (1992). Data requirements for seasonal discharge programs: an application of a region- alized sensitivity analysis. Water Resources Research, 28 (7), 1781-1789.

Mahajan, A. U., Chalapatiran, C. V., \& Gadkari, S. K. (1999). Mathematical modeling - A tool for coastal water quality management. Water Science and Technology, 40(2), 151-157.

McCuen, R. H., \& Beighley, R. E. (2003). Seasonal flow frequency analysis. Journal of Hydrology, 279, 43-56.

Melching, C. S., \& Yoon, C. G. (1996). Key sources of uncertainty in QUAL2E model of Passaic River. Journal of Water Resources Planning and Management, 122(2), 105-113.

Mujumdar, P. P., \& Vemula, V. R. S. (2004). Fuzzy waste load allocation model: Simulation-optimization approach. Journal of Computing in Civil Engineering, 18(2), 120-131.

Neelakantan, T. R., \& Pundarikanthan, N. V. (2000). Neural network-based simulation-optimization model for reservoir operation. Journal of Water Resources Planning and Management, 126(2), 57-64.

NRC (National Research Council) (2001). Assessing the TMDL approach to water quality management, $109 \mathrm{pp}$., National Academy Press.

Osidele, O. O., Zeng, W., \& Beck, M. B. (2003). Coping with uncertainty: a case study in sediment transport and nutrient load analysis. Journal of Water Resources Planning and Management, 129(4), 345-355.

Park, S. S., \& Lee, Y. S. (2002). A water quality modeling study of the Nakdong River, Korea. Ecological Modelling, 153, 65-75.

Reckhow, K., Arhonditsis, G., Kenney, M., Hauser, L., Tribo, J., $\& \mathrm{Wu}, \mathrm{C}$., et al. (2005). A predictive approach to nutrient criteria. Environmental Science and Technology, 39(9), 2913-2919.

Salas, J. D., \& Obeysekera, J. T. B. (1992). Conceptual basis of seasonal streamflow time series models. Journal of Hydrologic Engineering, 118(8), 1186-1194.

Shabman, L., \& Smith, E. (2003). Implications of applying statistically based procedures for water quality assessment. Journal of Water Resources Planning and Management, 129(4), 330-336.

Smakhtin, V. U. (2000). Estimating daily flow duration curves from monthly streamflow data. Water $S A, 26(1), 13-18$.

Smakhtin, V. U. (2001). Low flow hydrology: a review. Journal of Hydrology, 240, 147-186.

Smith, E. P., Ye, K., Hughes, C., \& Shabman, L. (2001). Statistical assessment of violations of water quality standards under Section 303(d) of the Clean Water Act. Environmental Science \& Technology, 35(3), 606-612.

Vogel, R. M., \& Fennessey, N. M. (1994). Flow-duration curves. I: New interpretation and confidence intervals. Journal of Water Resources Planning and Management, 120(4), 485-504.

Vogel, R. M., \& Fennessey, N. M. (1995). Flow duration curves. II: A review of applications in water resources planning. Water Resources Bulletin, 31(6), 1029-1039.

Warwick, J. J., \& Roberts, L. A. (1992). Computing the risks associated with wasteload allocation modeling. Water Resources Bulletin, 28(5), 903-914.

Yu, P. S., Yang, T. C., \& Wang, Y. C. (2002). Uncertainty analysis of regional flow duration curves. Journal of Water Resources Planning and Management, 128(6), 424-430. 